\title{
PERANCANGAN ENTERPRISE ARCHITECTURE MENGGUNAKAN METODE TOGAF ADM (STUDI KASUS PADA PT RMM)
}

\author{
Mohamad Afif \\ Program Studi Informatika Universitas Indraprasta PGRI \\ E-Mail: mohamadafif@gmail.com
}

\begin{abstract}
Abstrak
Pengembangan teknologi informasi di sebuah perusahaan sering kali tidak didasari oleh perancangan yang baik dan jelas bagaimana pengembangan di masa yang akan datang, dan apa saja yang dibutuhkan dalam pengembangan teknologi dan sistem informasi tersebut. Akibatnya teknologi dan sistem informasi yang dibangun menjadi tidak efisien bahkan kurang sesuai dengan misi dan visi perusahaan. Enterprise Architecture dibangun sebagai sebuah rencana induk perusahaan yang menjadi acuan atau pedoman di dalam membangun teknologi informasi tersebut. Enterprise Architecture merupakan rancangan teknologi informasi yang berpangkal dari rancangan proses bisnis perusahaan, dari rancangan inilah kebutuhan dan penyediaan informasi dibuat. Penyediaan kebutuhan dan informasi diwujudkan dalam bentuk sistem aplikasi dan penyediaan infrastruktur teknologi. Sebuah gambaran arsitektur memberikan nilai penting bagi sebuah perusahaan, yang memungkinkan manajemen untuk menyusun strategi yang lebih efektif dan melakukan pengawasan terhadap proses bisnis dan infrastruktur teknologi. TOGAF memberikan metode yang detil bagaimana membangun dan mengelola serta mengimplementasikan arsitektur enterprise dan sistem informasi yang disebut dengan Architecture Development Method. Metode ini berisikan sekumpulan aktivitas yang digunakan dalam memodelkan pengembangan arsitektur enterprise dan sebagai panduan untuk merencanakan, merancang, mengembangkan dan mengimplementasikan arsitektur sistem informasi untuk organisasi. Hasil dari perancangan ini adalah sebuah rancangan arsitektur teknologi informasi yang menjadi panduan bagi manajemen dalam menentukan anggaran belanja kebutuhan TI berdasarkan skala prioritas untuk mendukung efesiensi perusahaan.
\end{abstract}

Kata Kunci: Enterprise Architecture, Togaf ADM, Arsitektur Enterprise, Arsitektur Teknologi

\begin{abstract}
Information technology (IT) development in a company is often not based on good design on future development scenarios, technology development requirements, and information system. Information technology that has been built also inefficient according to company's vission and mission. Enterprise Architecture was built as a corporate master plan that became a reference or guidance in information technology development. Enterprise Architecture is an information technology company coming from the provision of needs and information embodied in form of application systems and provision of technology infrastructure. Architectural overview provides important values for company where management can develop more effective strategies in monitoring business processes and technological infrastructure. TOGAF provides detailed-methods of how to build, manage, and implement enterprise architecture and information systems called Architecture Development Method. This method contains some activities used in modeling the development of company's architecture. It is also a guide for planing, designing, developing, and implementing information systems architecture for organizations. The result of this design is an information technology architecture that becomes the guide for management in determining the budget of IT needs based on priority scale to support the efficiency of the company.
\end{abstract}

Keywords : Enterprise Architecture, Togaf ADM, Technology Architecture 


\section{Pendahuluan}

Teknologi Informasi dan komunikasi berperan penting dalam memperbaiki kinerja suatu perusahaan. Penggunaannya tidak terbatas pada proses otomatisasi terhadap akses informasi, tetapi juga menciptakan akurasi, kecepatan, dan kelengkapan sebuah sistem yang terintegrasi. Sebagai hasilnya proses bisnis suatu perusahaan akan lebih efisien, terukur dan fleksibel.

Persaingan bisnis dalam era informasi telah mencapai tahapan kompetisi yang ketat, di mana sistem pengelolaan bisnis secara konvensional tidak lagi memadai. Teknologi informasi memiliki potensi yang sangat besar untuk mentransformasikan seluruh aspek di dalam perusahaan dan memanfaatkannya untuk mencapai tujuan perusahaan.

Enterprise Architecture merupakan gambaran semua informasi penting dan perilaku yang terjadi di perusahaan. Sebuah gambaran arsitektur memberikan nilai penting bagi sebuah perusahaan, yang memungkinkan manajemen untuk menyusun strategi yang lebih efektif, mengawasi proses bisnis dan infrastruktur teknologi dengan pemahaman yang jelas tentang dampak dari perubahannya. Termasuk pada kebijakan dan prosedur yang harus dikomunikasikan kepada seluruh karyawan agar semua orang dapat berada pada konsep yang sama.

Enterprise Architecture bisa menjadi enabler yang menyediakan model bisnis yang baru dengan memperhatikan pengaruh Teknologi Informasi terhadap bisnis. Memiliki kemampuan untuk melakukan adaptasi terhadap perubahan organisasi, dan pertumbuhan dalam pasar, bisnis, dan teknologi yang dinamis, yang berkelanjutan dengan prinsip dan struktur arsitektur yang terus berlaku. Melibatkan sejumlah orang dengan komposisi yang berbeda dari manajemen hingga ke pakar Teknologi Informasi.

TOGAF memberikan metode yang detil bagaimana membangun dan mengelola serta mengimplementasikan arsitektur enterprise dan sistem informasi yang disebut dengan Architecture Development Method (ADM) (Josey, 2011). ADM merupakan metode generik yang berisikan sekumpulan aktivitas yang digunakan dalam memodelkan pengembangan arsitektur enterprise. Metode ini juga dibisa digunakan sebagai panduan untuk merencanakan, merancang, mengembangkan dan mengimplementasikan arsitektur sistem informasi untuk organisasi.

Perancangan Enterprise architecture bertujuan untuk memberikan panduan bagi Manajer IT dan pengambil kebijakan terhadap perencanaan pembangunan infrastruktur teknologi informasi ke depan yang selaras dengan kebutuhan bisnis perusahaan. Bagi PT RMM rancangan ini memberikan manfaat bagi manajemen di dalam menyusun rencana anggaran belanja kebutuhan infrastruktur Teknologi Informasi berdasarkan skala prioritas dalam upaya menekan pembelian yang tidak perlu sehingga bisa lebih efesien dan tidak terjadi pemborosan.

\section{Tinjauan Pustaka}

\section{Arsitektur Enterprise}

Arsitektur merupakan perancangan dari suatu benda atau merepresentasikan suatu gambaran yang sesuai dengan suatu obyek sehingga dapat diperoleh hasil yang sesuai dengan kebutuhan dan berkualitas. Arsitektur menyiratkan suatu perencanaan yang diwujudkan dengan model dan gambar dari komponen dari sesuatu dengan berbagai sudut pandang. Enterprise mengandung arti keseluruhan komponen pada suatu organisasi dibawah kepemilikan dan kontrol organisasi tunggal (Yunis \& Surendro, 2009).

Dalam mengimplementasikan arsitektur enterprise sebaiknya organisasi mengadopsi sebuah metode atau framework yang bisa digunakan dalam melakukan pengembangan arsitektur enterprise tersebut. Dengan adanya metode enterprise arsitektur organisasi diharapkan dapat 
mengelola sistem yang kompleks dan dapat menyelaraskan bisnis dan TI yang akan diinvestasikan (Kourdi, 2007).

Hasil dari arsitektur enterprise ini terdiri dari dokumen-dokumen seperti gambar, diagram, model, serta dokumen dalam bentuk teks yang akan menjelaskan seperti apa sistem informasi yang dibutuhkan suatu organisasi. Arsitektur enterprise akan dijadikan sebagai acuan bagi pengembangan sistem informasi. Pengembangan sistem tanpa memiliki arsitektur yang baik akan sulit untuk mencapai hasil yang maksimal.

\section{The Open Group Architecture Enterprise (TOGAF)}

TOGAF memberikan metode yang lengkap bagaimana membangun, mengelola dan menerapkan arsitektur enterprise dan sistem informasi yang disebut dengan Architecture Development Method (ADM). ADM merupakan hasil dari kontribusi secara terus menerus dari banyak pelaksana arsitektur. Metode ini menggabungkan elemen dari TOGAF dengan kebutuhan bisnis dan TI organisasi. ADM juga bisa digunakan sebagai panduan atau alat untuk merencanakan, merancang, mengembangkan, dan menenerapankan arsitektur sistem informasi untuk organisasi (Greefhorst, 2013).

TOGAF ADM seperti ditunjukkan pada Gambar 1, juga merupakan metode yang fleksibel yang dapat mengidentifikasi berbagai macam teknik pemodelan yang digunakan dalam perancangan, karena metode ini bisa disesuaikan dengan perubahan dan kebutuhan selama perancangan dilakukan.

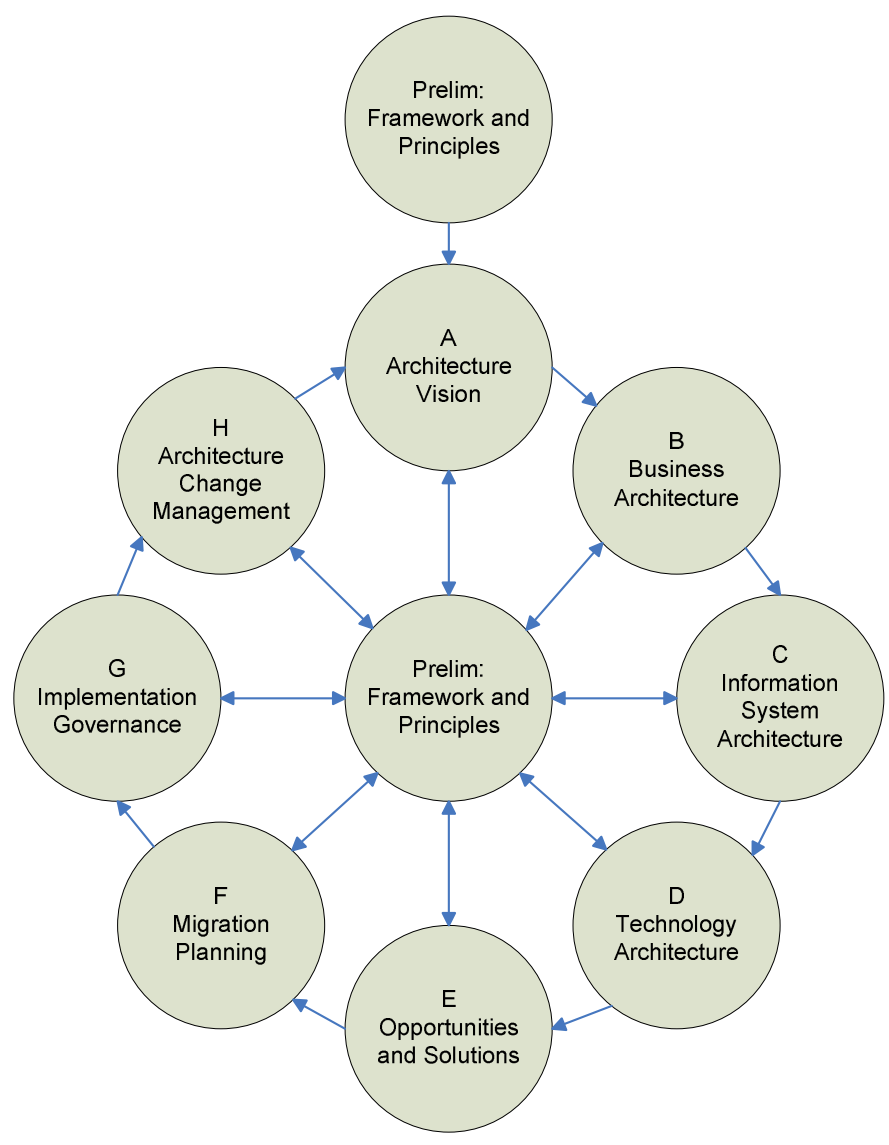

Gambar 1. TOGAF Architecture Development Method (Land et al. 2009)

TOGAF ADM juga menyatakan visi dan prinsip yang jelas tentang bagaimana melakukan pengembangan arsitektur enterprise, prinsip tersebut digunakan sebagai ukuran dalam 
menilai keberhasilan dari pengembangan arsitektur enterprise oleh organisasi (Josey, 2011). Prinsip-prinisip tersebut dapat dijelaskan sebagai berikut:

1. Prinsip Enterprise

Pengembangan arsitektur yang dilakukan diharapkan mendukung seluruh bagian organisasi, termasuk unit-unit organisasi yang membutuhkan.

2. Prinsip Teknologi Informasi (TI)

Lebih mengarahkan konsistensi penggunaan TI pada seluruh bagian organisasi, termasuk unit-unit organisasi yang akan menggunakan.

3. Prinsip Arsitektur

Merancang arsitektur sistem berdasarkan kebutuhan proses bisnis dan bagaimana menerapkannya.

TOGAF ADM terdiri dari delapan fase yang berbentuk siklus yaitu Architecture Vision, Business Architecture, Information System Architecture, Technology Architecture, Opportunities and Solution, Migration Planning, Implementation Governance,dan Architecture Change Management.

\section{Metodologi Penelitian}

Dalam mengembangkan Arsitektur Enterprise PT RMM, ada beberapa tahapan proses yang dilalui sebagai berikut:

1. Fase Pendahuluan (Preliminary Phase) - Ruang Lingkup Enterprise, mendefinisikan area bisnis berdasarkan wawancara dan observasi

2. Pengembangan arsitektur TI

a. Visi Arsitektur (Architecture vision), adalah gambaran umum bagaimana TI diterapkan untuk mendukung strategi bisnis organisasi atau perusahaan

b. Arsitektur Bisnis (Business architecture), adalah model operasional organisasi yang merealisasikan strategi bisnis

c. Arsitektur Sistem Informasi (Information system architecture), adalah struktur aplikasi dan data yang dibutuhkan untuk menjalankan Arsitektur Bisnis organisasi

d. Arsitektur Teknologi (Technology architecture), adalah konfigurasi infrastruktur yang dibutuhkan untuk menjalankan aplikasi-aplikasi pada Arsitektur Sistem Informasi

3. Gap analysis. Melakukan evaluasi berbagai kemungkinan pelaksanaan, mengidentifikasi proyek-proyek implementasi yang mungkin dilakukan, mengevaluasi peluang usaha yang berkaitan dengan proyek, memilih alternatif implementasi, mendefinisikan strategi implementasi dan rencana implementasi.

4. Perencanaan proses migrasi ke arsitektur baru, yaitu penyusunan proyek-proyek berdasarkan prioritas dari berbagai perspektif (biaya, manfaat, serta resiko)

5. Pengawasan proyek-proyek implementasi, penyusunan rekomendasi untuk pelaksanaan tata kelola implementasi yang sudah dilakukan (tata kelola organisasi, TI, arsitektur).

6. Re-evaluation relevansi arsitektur dan trend teknologi, melakukan pengawasan terhadap perkembangan teknologi dan perubahan lingkungan sosial.

\section{Hasil dan Pembahasan}

PT RMM memiliki bisnis inti di bidang penerbitan surat kabar dan berita online. Disamping itu juga memiliki usaha di bidang penerbitan buku, televisi dan majalah. Proses-proses inti yang terjadi pada perusahaan ini adalah : proses pengolahan berita, termasuk di dalamnya perencanaan, pengumpulan, pengeditan dan penerbitan berita. Proses inti lainnya adalah pemasangan iklan, pencetakan surat kabar dan penerbitan di media online.

Permasalahan strategis yang dihadapi perusahaan adalah pada kecepatan dan kemudahan dalam proses pengumpulan, penerbitan dan pengiriman berita. 


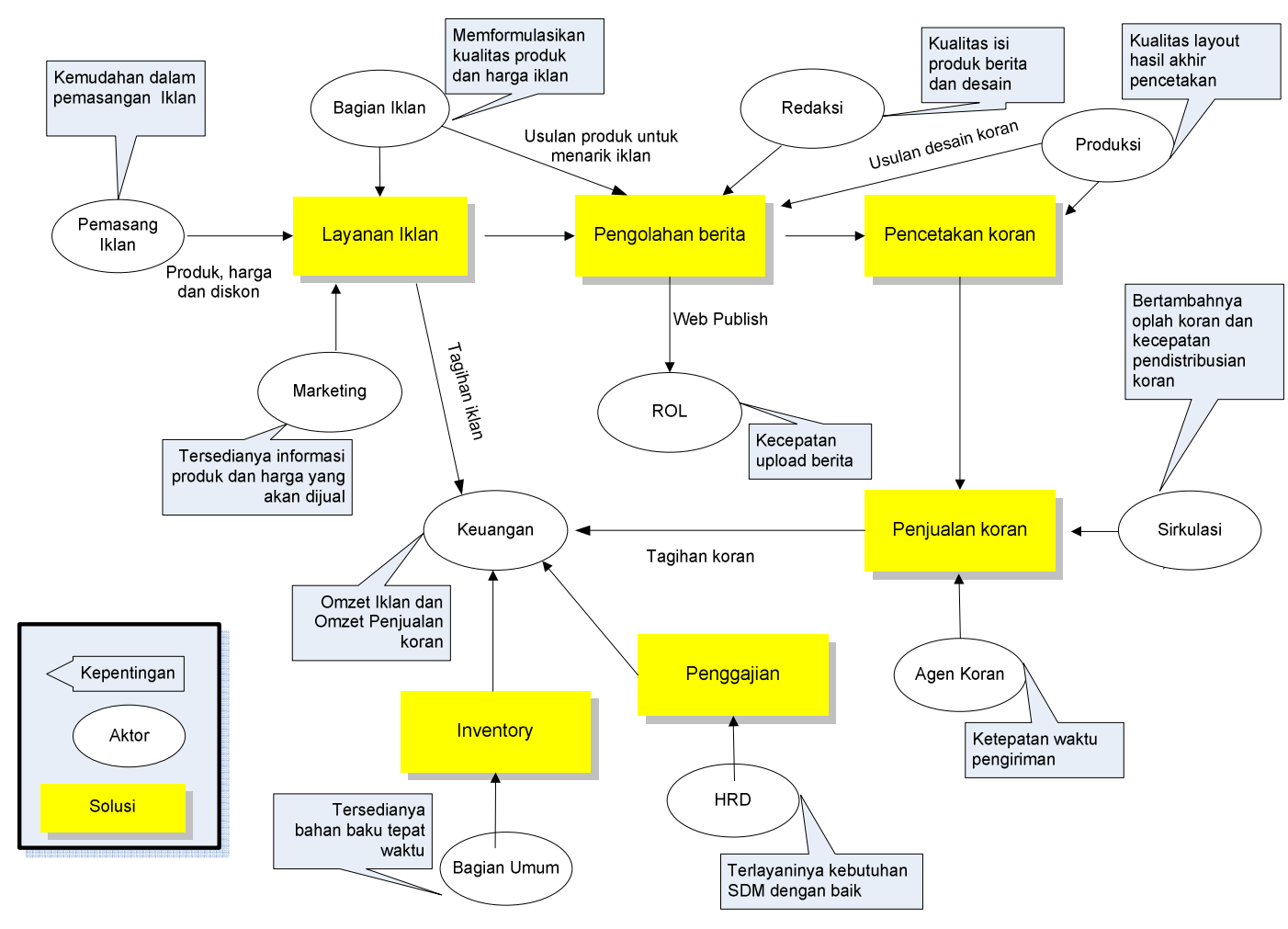

Gambar 2. Rich Picture Identifikasi Key IT Solution

Berikut ini adalah proses-proses penting dan kritikal yang terjadi di PT RMM :

1. Proses pemasangan iklan (Sistem Manajemen Iklan )

Dalam sistem ini, data pemasang iklan dan jenis iklan yang diambil disimpan dalam database untuk kemudian data ini digunakan sebagai acuan dalam menentukan template layout koran. Dalam proses pembuatan template layout koran ini redaktur akan mendapatkan jatah tulisan yang tersedia atau tidak dan berapa jumlah karakter berita yang tersedia. Pemasangan iklan di halaman dalam akan didahulukan dari pada berita itu sendiri.

2. Proses pengolahan berita ( Sistem Editorial)

Pada bagian ini proses produksi berita dilakukan. Mulai dari perencanaan, pengumpulan, editing berita dan layout halaman. Hasil akhir dari proses ini adalah berita yang siap ditayangkan baik itu ke dalam koran cetak, online maupun ke dalam bentuk yang lain.

\section{Proses pra cetak}

Pada proses ini hasil layout halaman yang sudah selesai diedit oleh redaktur kemudian dikonversi kedalam bentuk PDF kemudian diupload ke server untuk diambil datanya oleh bagian percetakan yang berbeda lokasi dengan kantor pusat.

\section{Proses pencetakan koran}

Proses mencetak koran di percetakan berdasarkan pada plate yang sudah disiapkan sebelumnya pada proses pra cetak.

\section{Proses penjualan koran}

Sistem ini mengelola informasi penjualan koran, berhubungan dengan agen-agen koran sebagai mitra kerja PT RMM didalam mendistribusikan koran cetak sampai kepada pembaca berlangganan maupun eceran. 


\section{Proses keuangan dan accounting ( ERP)}

Sistem ini mengelola informasi keuangan, dan sistem informasi akunting termasuk didalamnya AP ( Account Payable), AR ( Account Receivable) dan General Ledger

\section{Proses pengolahan data dan dokumentasi ( Riset dan Pengembangan )}

Sistem ini mengelola data-data riset terhadap jumlah pembaca, tren koran masa depan, informasi pesaing dan lain-lain

8. Proses pengolahan foto, ilustrasi dan dokumentasi ( Redaksi - Bagian pengolahan foto )

Pada bagian ini foto, ilustrasi dan semua yang berhubungan dengan gambar, grafik dan sebagainya diproses. Termasuk didalamnya proses dokumentasi ke dalam database

\section{Proses penerbitan berita online}

Pada proses ini hasil akhir dari teks berita yang sudah diedit oleh redaktur siap ditayangkan ke internet lewat content management system

10. Proses absensi dan penggajian ( Bagian Sumber Daya Manusia )

Sistem yang digunakan untuk mengelola sumber daya manusia, termasuk di dalamnya penggajian

\section{Proses inventory ( Bagian Umum )}

Bagian ini berhubungan dengan supplier yang mendukung proses kerja yang ada di tiap departemen, termasuk didalamnya suplai bahan baku kertas sebagai dasar dalam pencetakan koran.

\section{Visi Arsitektur}

Visi arsitektur memberikan gambaran bagaimana key IT solutions berperan dalam proses bisnis strategis perusahaan.

Tabel 1. Business Solution Identification

\begin{tabular}{llll}
\hline No & Judul & Ukuran & Sasaran Perbaikan \\
\hline 1 & Penyediaan berita kurang lancar & $\begin{array}{l}\text { Berita tersedia 7 hari 24 jam. Total } \\
500-800 \text { berita }\end{array}$ & $\begin{array}{l}\text { Perbaikan sistem } \\
\text { pengiriman berita dan } \\
\text { infrastuktur jaringan }\end{array}$ \\
\hline 2 & $\begin{array}{l}\text { Iklan tidak tayang sesuai permintaan } \\
\text { klien }\end{array}$ & $\begin{array}{l}\text { Penanyangan iklan sesuai dengan } \\
\text { penempatan yang sudah ditentukan }\end{array}$ & $\begin{array}{l}\text { Perbaikan SOP dan } \\
\text { monitoring }\end{array}$ \\
\hline 3 & Distribusi koran terlambat & $\begin{array}{l}\text { Waktu pencetakan sesuai deadline. } \\
\text { Dibagi menjadi 3 tahapan } \\
\text { pencetakan, sore, malam dan } \\
\text { dinihari }\end{array}$ & $\begin{array}{l}\text { Ketepatan deadline berita, } \\
\text { pengiriman berita }\end{array}$ \\
& & Outstanding minimal 1 bulan & $\begin{array}{l}\text { Perbaikan sistem } \\
\text { keuangan }\end{array}$ \\
\hline 4 & Penagihan piutang & $\begin{array}{l}\text { Mendapatkan laporan hak } \\
\text { cuti,tunjangan dll }\end{array}$ & Perbaikan sistem SDM \\
\hline 6 & $\begin{array}{l}\text { Karyawan tidak mendapatkan } \\
\text { hak cuti,tunjangan,gaji dll }\end{array}$ & info & \\
\hline
\end{tabular}

Tabel 2. IT Solution Identification

\begin{tabular}{lll}
\hline No & Sasaran Perbaikan & Pola Solusi \\
\hline 1 & $\begin{array}{l}\text { Perbaikan sistem pengiriman berita dan } \\
\text { infrastruktur jaringan }\end{array}$ & $\begin{array}{l}\text { Aplikasi Sistem Editorial terintegrasi mencakup pasokan dan pengiriman } \\
\text { berita melalui email,web, whatsapp, android }\end{array}$ \\
\hline 2 & Perbaikan SOP iklan & Mengintegrasikan sistem iklan ke dalam sistem editorial \\
\hline 2 & Distribusi koran terlambat & Pembuatan sistem deadline sebagai pengingat \\
\hline 3 & Notifikasi artikel & Pembuatan sistem notifikasi artikel yang dimuat \\
\hline 4 & Perbaikan sistem keuangan & $\begin{array}{l}\text { Sistem terintegrasi yang mencakup keuangan, sirkulasi, purchasing, } \\
\text { SDM, advertising dan editorial }\end{array}$ \\
\hline 6 & Perbaikan sistem SDM & Aplikasi sistem SDM terintegrasi \\
\hline
\end{tabular}


Perancangan Arsitektur TI memerlukan panduan berupa prinsip-prinsip yang diturunkan dari konsep key IT solutions untuk memastikan bahwa teknologi yang diterapkan dapat mendukung key IT solutions. Prinsip-prinsip arsitektur juga mempertimbangkan kondisi TI organisasi saat ini. Selain itu juga mengutamakan pemanfaatan aset-aset TI yang sudah dimiliki dan meminimalkan resiko migrasi.

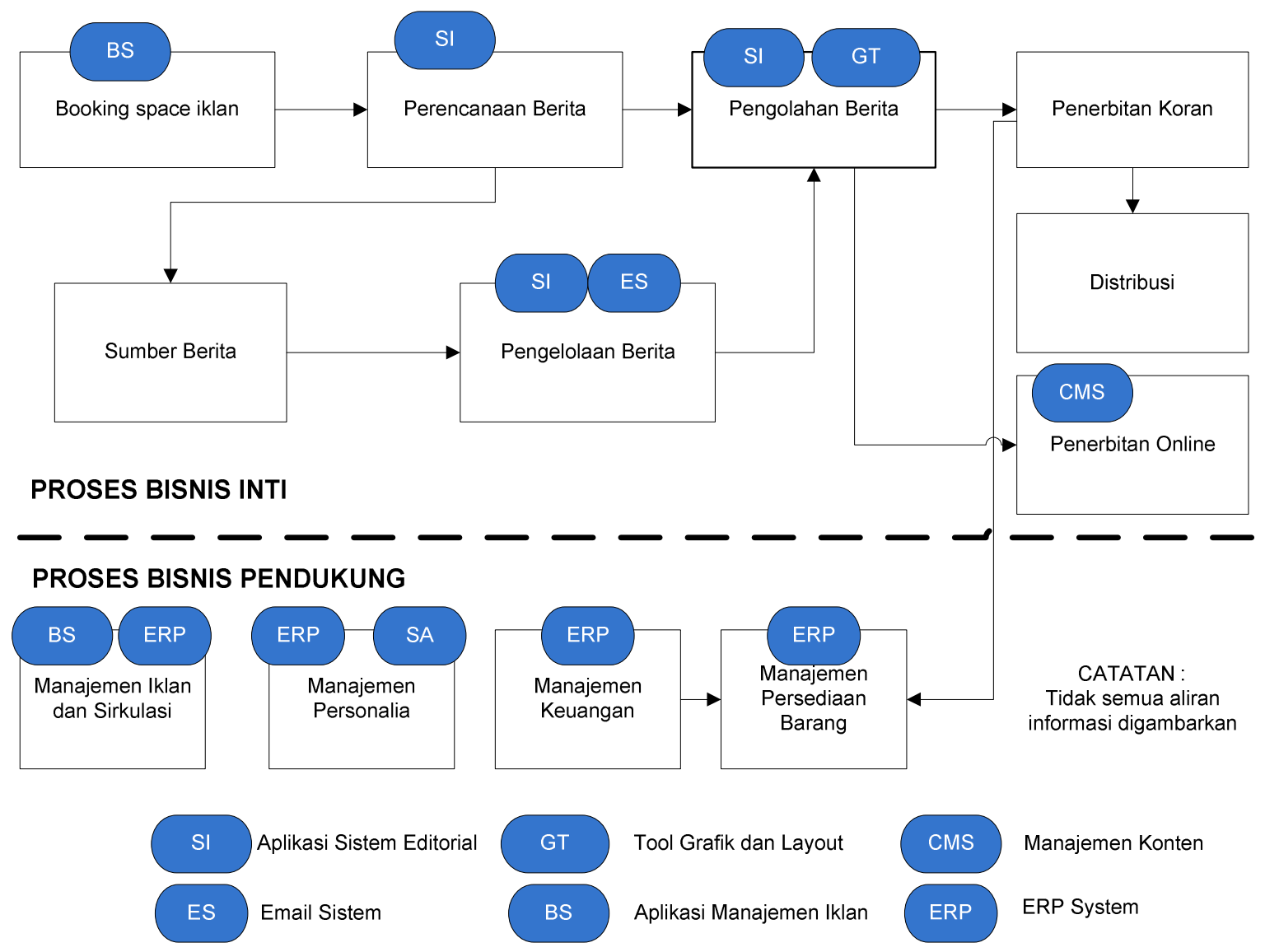

Gambar 3. Application Solution

\section{Information System Architecture}

Arsitektur sistem informasi mendeskripsikan sistem-sistem aplikasi dan perannya dalam mendukung proses-proses bisnis berupa teknologi atau konsep aplikasi kunci ( key application ) yang dibutuhkan. Struktur logis sistem informasi yang berupa gambaran pertukaran informasi antar sistem aplikasi, dan antara sistem-sistem aplikasi dengan pengguna. Serta struktur atau komposisi modul-modul sistem informasi. Solusi aplikasi dapat mengadopsi best practice di industri. 


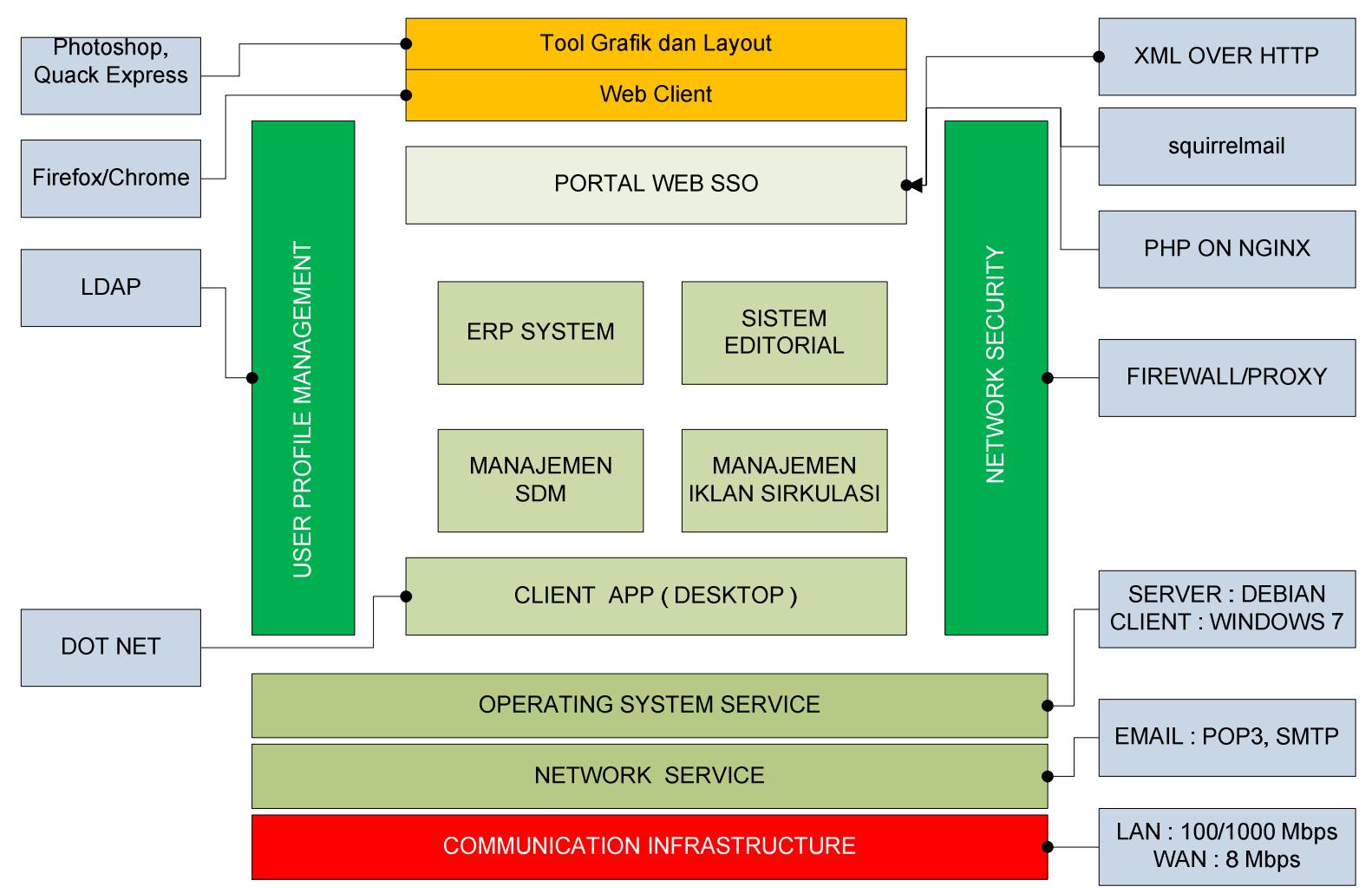

Gambar 4. Overall Architecture

\section{Technology Architecture}

Arsitektur teknologi diperinci sampai ke komponen hardware. Kemudian melakukan pemetaan kebutuhan hardware sistem aplikasi. Dari hasil pemetaan ini bisa digunakan untuk melakukan identifikasi hardware yang dapat dipakai bersama, dan memungkinkan identifikasi mekanisme integrasi antar komponen sistem aplikasi yang saling berhubungan.

\section{Gap Analysis}

Melakukan identifikasi peluang pemanfaatan aset TI yang ada dan solusi baru yang harus dikembangkan. Pada gap analysis ini muncul daftar kegiatan implementasi arsitektur yang diperoleh dengan membandingkan antara arsitektur TI ideal dengan arsitektur saat ini. Tabulasi gap dapat diterapkan pada proses bisnis, sistem informasi, maupun komponen infrastruktur.

\section{Simpulan dan Saran}

\section{Simpulan}

Enterprise Architecture memberikan gambaran tentang teknologi informasi yang akan dibangun di PT RMM dengan harapan memberikan efesiensi dan menjadi acuan dalam pengembangan TI di masa mendatang.

\section{Saran}

Hasil perancangan ini masih jauh dari sempurna dan perlu membuat perbandingan dengan metode lain agar dihasilkan perancangan Enterprise Architecture yang lebih baik. 


\section{Daftar Pustaka}

Bernard, S. (2004). An Introduction to Enterprise Architecture.

Ghasemi, M., Shafeiepour, V., Aslani, M., \& Barvayeh, E. (2011). The impact of Information Technology (IT) on modern accounting systems. ScienceDirect .

Greefhorst, D. (2013). TOGAF, \& Major IT Frameworks, Architecting the Family. ITpreneurs .

Hamidi, F., Meshkat, M., Rezaee, M., \& Jafari, M. (2011). Information Technology in Education. ScienceDirect .

Josey, A. (2011). Togaf Version 9.1 Enterprise Edition. Open Group .

Kalkana, A., Erdil, O., \& Çetinkaya, Ö. (2011). The Relationships Between Firm Size, Prospector Strategy, Architecture of Information Technology and Firm Performance. ScienceDirect .

Katili. (2004). Pengembangan Arsitektur Informasi Perusahaan Aspek Fungsi, Jaringan, Motivasi, AJB Bumi Putera 1912.

Kourdi, H. (2007). Framework fo Enterprise Architecture. IEEE .

Mostafapour, M. A., Rezaei, H., \& Ghabousi, S. A. (2012). The Application of Information Technology and Its Role on Entreprenesurs Success. ScienceDirect .

Osvalds, G. (2001). Definition of Enterprise Architecture-Centric Models for The Systems Engineer. TASC Inc .

Pollalis, Y. A., \& Macris, A. (2008). Strategic Planning for Information Resources: Enhancing Managers Participation through Ontology-based Modeling. International Journal of Technology Management .

Rennings, K., Kemp, R., Bartolomeo, M., Hemmelskamp, J., \& Hitchens, D. (2004). Blueprints for an Integration of Science, Technology and Environmental Policy (BLUEPRINT). Germany.

Robert K, Y. (2001). Case Study Research Design and Methods. Washington: Cosmos Corporation.

Setiawan. (2009). Perancangan Strategis Sistem Informasi IT Telkom untuk menuju World Class University. Seminar Nasional Aplikasi Teknologi Informasi , 97-101.

Varveris, L., \& Harrison, D. (2005). Building Enterprise Architectures with TOGAF. White Paper .

Yunis, R., \& Surendro, K. (2009). Perancangan Model Enterprise Architecture dengan Togaf. Seminar Nasional Aplikasi Teknologi Informasi 2009 (SNATI 2009) .

Zachman. (2003). Zachman Framework for Enterprise, Primer for Enterprise Engineering and Manufacturing. 